\title{
Heterogeneous Nucleation of $\alpha$-Al Grain on Primary $\alpha$-AIFeMnSi Intermetallic Investigated Using 3D SEM Ultramicrotomy and HRTEM
}

\author{
WENCHAO YANG, SHOUXUN JI, XIAORONG ZHOU, IAN STONE, \\ GEOFF SCAMANS, GEORGE E. THOMPSON, and ZHONGYUN FAN
}

\begin{abstract}
Microstructural examination of the Al-5.3Mg-2.4Si- $0.6 \mathrm{Mn}-1.0 \mathrm{Fe}$ alloy in the die-cast condition revealed that a significant number of the primary $\alpha$-AlFeMnSi intermetallic particles were found inside both the coarse $\alpha$-Al dendrite fragments formed in the shot sleeve and the fine $\alpha$-Al grains formed in the die cavity. The heterogeneous nucleation of $\alpha$-Al phase on primary $\alpha$-AlFeMnSi intermetallic particle was further investigated experimentally. 3-Dimension (3D) scanning electron microscopy ultramicrotomy revealed that the probability of finding at least one primary $\alpha$-AlFeMnSi intermetallic particle inside each $\alpha$-Al grain was almost 90 pct. The detailed microstructural analysis identified the primary $\alpha$-AlFeMnSi intermetallic particle as the $\alpha-\mathrm{Al}_{12}(\mathrm{Fe}, \mathrm{Mn})_{3} \mathrm{Si}$ composition with a body-centered cubic structure and a lattice parameter of $a=1.265 \mathrm{~nm}$. It was found that the primary $\alpha-\mathrm{Al}_{12}(\mathrm{Fe}, \mathrm{Mn})_{3} \mathrm{Si}$ intermetallic particle had a faceted morphology with $\{110\}$ planes exposed as its natural surfaces. High resolution transmission electron microscopy further confirmed that the crystallographic orientation relationship between $\alpha-\mathrm{Al}_{12}(\mathrm{Fe}, \mathrm{Mn})_{3} \mathrm{Si}$ intermetallic particle and $\alpha$-Al phase was: $[111]_{\alpha-\mathrm{AlFeMnSi}} / /[110]_{\mathrm{Al}}$ and $(1 \overline{1} 0)_{\alpha-\mathrm{AlFeMnSi}} \sim 6$ deg from $(1 \overline{1} 1)_{\alpha-\mathrm{Al}}$, and the corresponding interface between two phases could be confirmed as a semi-coherent interface with a lattice misfit of 2.67 pct at $933 \mathrm{~K}\left(660{ }^{\circ} \mathrm{C}\right)$, which was considerably smaller than the theoretical limit $(5.7 \mathrm{pct})$ for epitaxial nucleation. Finally, based on these experimental evidences and the epitaxial nucleation model, we concluded that the primary $\alpha-\mathrm{Al}_{12}(\mathrm{Fe}, \mathrm{Mn})_{3} \mathrm{Si}$ intermetallic particles were both potent and effective nucleating substrates for the $\alpha$-Al phase.
\end{abstract}

DOI: $10.1007 / \mathrm{s} 11661-014-2346-6$

(C) The Minerals, Metals \& Materials Society and ASM International 2014

\section{INTRODUCTION}

UNDERSTANDING heterogeneous nucleation is of great importance to both solidification science and solidification processing for providing high-quality metallic materials. However, our current understanding of heterogeneous nucleation has been very limited mainly due to experimental difficulties. ${ }^{[1]}$ The classical heterogeneous nucleation theory (CNT) was first proposed in $1926^{[2,3]}$ on the basis of balancing interfacial energy with the change of volume free energy. The potency of the nucleating substrate in the classical nucleation theory was estimated by the contact angle. However, it is realized that the CNT is not applicable for potent nucleation substrates, where the contact angle

WENCHAO YANG, Research Fellow, SHOUXUN JI and IAN STONE, Lecturers, GEOFF SCAMANS and ZHONGYUN FAN, Professors, are with The EPSRC Centre - LiME, BCAST, Brunel University, Uxbridge, Middlesex UB8 3PH, U.K. Contact e-mail: wenchao.yang@brunel.ac.uk, yangwenchao1985@163.com XIAORONG ZHOU, Reader, and GEORGE E. THOMPSON, Professor, are with the Corrosion and Protection Centre, School of Materials, The University of Manchester, Manchester M13 9PL, U.K.

Manuscript submitted November 25, 2013. is so small that the creation of a spherical cap becomes unphysical. ${ }^{[4]}$ Moreover, CNT is unable to answer the question why not every particle in the melt forms a grain. To answer this question, Maxwell and Hellawel1 ${ }^{[5]}$ developed in 1975 a simple model by considering the quantitative effect of latent heat release on the initiation of grains. They identified that the melt recalescence due to latent heat released by the growth of the initially nucleated grains was responsible for non-nucleation of the majority of the particles. However, they were not able to provide a criterion for selecting the substrates which will nucleate first. Based on the Maxwell-Hellawell model, Greer et al. ${ }^{[6]}$ developed the free growth model in 2000 to describe grain initiation. They demonstrated theoretically that the undercooling required to overcome the energy barrier to free growth was inversely proportional to the diameter of substrate. This means that the largest particle would be the first to grow freely as soon as the required undercooling was reached, followed by progressively smaller ones as the undercooling was increased.

Although macroscopic approaches described previously are helpful to understand the energetics of the nucleation process, heterogeneous nucleation is basically an atomic-level activity, and it can only be understood once we know the exact process of how atoms in the liquid phase come together to form a crystalline 
solid nucleus. In light of the importance of crystallographic matching across the substrate/solid interface in heterogeneous nucleation, ${ }^{[7,8]}$ Fan developed recently the epitaxial model for heterogeneous nucleation on potent substrates. ${ }^{[9]}$ In this model, heterogeneous nucleation on potent substrates was described as a constrained layer-by-layer growth process, and nucleation if completed by introduction of dislocations at the solid/ substrate interface before a critical solid layer thickness. ${ }^{[9]}$ This epitaxial nucleation model demonstrated clearly the importance of lattice misfit between the substrate and the solid and provided the approaches to manipulate the lattice misfit to enhance heterogeneous nucleation.

Experimental investigation of heterogeneous nucleation has proven to be very difficult since nucleation occurs at very small time and length scale, and usually in a non-opaque system at high temperature. Our current knowledge on heterogeneous nucleation is mainly from the practical development of effective grain refiners for structural refinement. Today, addition of grain refiners (inoculation) in both continuous and shape casting is a common industrial practice. ${ }^{[10]}$ For instance, Al-Ti-B or $\mathrm{Al}-\mathrm{Ti}-\mathrm{C}$ master alloys are added to Al-alloys, $\mathrm{Zr}$ or $\mathrm{C}$ to $\mathrm{Mg}$-alloys, ferrosilicon to cast iron, $\mathrm{Fe}, \mathrm{Co}$ or $\mathrm{Zr}$ to $\mathrm{Cu}$-alloys, $\mathrm{P}$ to hypereutectic Al-Si alloys, and $\mathrm{Ti}$ to $\mathrm{Zn}$-alloys. However, there is no consensus on the precise mechanisms responsible for the grain refinement.

It is obvious that the acquisition of the observable nuclei and the characterization of nuclei in the nucleated phase are equally important in discourse a nucleation event. However, because the nuclei inside the nucleated solid phase are always at micro- or even nano-scales, the dynamic direct observation for these nuclei is technically difficult to have a reliable conclusion. Recently, a 3D scanning electron microscopy (SEM) ultramicrotomy technology combining with the low voltage SEM was developed to investigate the morphology of the precipitates at various stages of de-alloying, ${ }^{[11,12]}$ in which a series of backscattered electron SEM images can be continuously taken by sliding the sample with a consistent depth in nano-scale. This offers an opportunity to study the phase morphology by assembling the SEM images to form a three dimensional morphology. If foreign particles can be nuclei in an as-cast microstructure, the nuclei will be observed in at least one image obtained by continuous sectioning. It should be noted that, to make the sample for 3D SEM ultramicrotomy observation, the grains need to be fine, and the nuclei need to provide sufficient numbers in the backscattered electron images.

More recently, when examining the effect of iron on the microstructure and mechanical properties of $\mathrm{Al}-\mathrm{Mg}-\mathrm{Si}-$ Mn alloys processed by high pressure die casting (HPDC), ${ }^{[13]}$ it was found that both the coarse $\alpha$-AlFeMnSi intermetallics formed in the shot sleeve and the fine $\alpha$-AlFeMnSi intermetallic phase formed in the die cavity were frequently observed inside the $\alpha$-Al grains. This suggests that the $\alpha-\mathrm{AlFeMnSi}$ intermetallic particles may act as the nucleation sites for the $\alpha$-Al phase, although many $\alpha$-AlFeMnSi intermetallic particles are located at the $\alpha$-Al grain boundaries. As iron in aluminum alloys is essentially detrimental for the mechanical properties due to the formation of intermetallic phases along the grain boundary, ${ }^{[14]}$ it is obviously beneficial in eliminating their disadvantages if the iron-rich intermetallic compounds can be positively used as potential sites for heterogeneous nucleation of the $\alpha$-Al phase.

In this paper, we investigate experimentally the heterogeneous nucleation of $\alpha$-Al phases on $\alpha$-AlFeMnSi intermetallic particles in a die-cast $\mathrm{Al}-5.3 \mathrm{Mg}-2.4 \mathrm{Si}-$ $0.6 \mathrm{Mn}$ alloy. After establishing the nature of $\alpha-\mathrm{AlFeMnSi}$ intermetallic particle, we provide the evidence of heterogeneous nucleation of $\alpha$-Al phase on $\alpha$-AlFeMnSi intermetallic particle by using the 3D SEM ultramicrotomy and high resolution transmission electron microscopy (HRTEM) interfacial analysis. The discussion will be focused on understanding heterogeneous nucleation in the light of the epitaxial nucleation model.

\section{EXPERIMENTAL}

Al-5.3Mg-2.4Si-0.6Mn-1.0Fe (wt pet) alloy was prepared by melting the ingots of commercial pure $\mathrm{Al}$, pure $\mathrm{Mg}$, and the Al-15 wt pet Si, Al-20 wt pet $\mathrm{Mn}$ and $\mathrm{Al}-80$ wt pet $\mathrm{Fe}$ master alloys at $1023 \mathrm{~K}\left(750^{\circ} \mathrm{C}\right)$ for 2 hours. A Frech $4500 \mathrm{kN}$ HPDC machine was used to produce the final as-cast samples with a pouring temperature of $933 \mathrm{~K}\left(660^{\circ} \mathrm{C}\right)$. More detailed descriptions about the sample preparation can be found in Reference 13.

Microstructures of the samples were investigated by optical microscopy, conventional SEM, 3DSEM ultramicrotomy, X-ray diffraction (XRD), transmission electron microscopy (TEM), and HRTEM.

SEM was carried out on a Zeiss Supera 35 instrument equipped with a field emission gun and energy dispersive spectroscopy (EDS) facilities and operated at an accelerating voltage of $15 \mathrm{kV}$ to indentify the composition and morphology of $\alpha$-AlFeMnSi intermetallic particles on a polished sample. In situ spectroscopy calibration was performed in each session of the EDS quantification using pure copper. To minimize the influence from the interaction volume during the EDS quantification, five point analyses on selected intermetallics were conducted for each phase, and the average was taken as the measurement.

3D SEM ultramicrotomy as a new technique was first used to investigate the heterogeneous nucleation. In this technique, serial cross-sections were produced by a sharp diamond knife on a Leica ultracut ultramicrotome, cutting through the volume of interest in $30 \mathrm{~nm}$ steps. Volumetric SEM images from a set of sequential ultramicrotomed serial surfaces were acquired at an operating beam energy of $1.5 \mathrm{keV}$ and a filtering grid bias voltage of $0.5 \mathrm{kV}$, using a backscattered electron detector.

XRD and HRTEM were used to identify the structure of the $\alpha$-AlFeMnSi intermetallic particle and its lattice parameter. At the same time, HRTEM was also used to investigate the orientation relationships and the interface between $\alpha$-AlFeMnSi intermetallic particle and $\alpha$-Al phase. XRD was carried out with Bruker D8 Advance powder diffractometer equipped with $\mathrm{Cu} \mathrm{K}_{\alpha}$ radiation.TEM and HRTEM examinations were performed on a Tecnai FEG F30 TEM instrument equipped with 
EDS facility operated at $300 \mathrm{kV}$ accelerating voltage. To prepare thin foils for TEM and HRTEM examination, slices cut from the as-cast HPDC samples were mechanically ground and cut into 3-mm diameter disks. These disks were then ground to a thickness of less than $100 \mu \mathrm{m}$ and finally ion-beam thinned on a Gatan precision ion polishing system at a voltage of $5.0 \mathrm{kV}$ and an incident angle of 4 to $6 \mathrm{deg}$.

\section{RESULTS}

\section{A. Morphology and Composition of the $\alpha$-AlFeMnSi Intermetallics in HPDC Sample}

Figure 1(a) is an optical micrograph showing the microstructure of the die-cast Al-5.3Mg-2.4Si-0.6Mn$1.0 \mathrm{Fe}$ alloy. The $\alpha-\mathrm{Al}$ phase exhibits two distinctive morphologies: one is coarse dendrite fragment by fragmentation of dendrites formed in the shot sleeve after pouring under a cooling rate around $10^{2} \mathrm{~K} / \mathrm{s}$, and the other one is fine globular grain formed inside the die
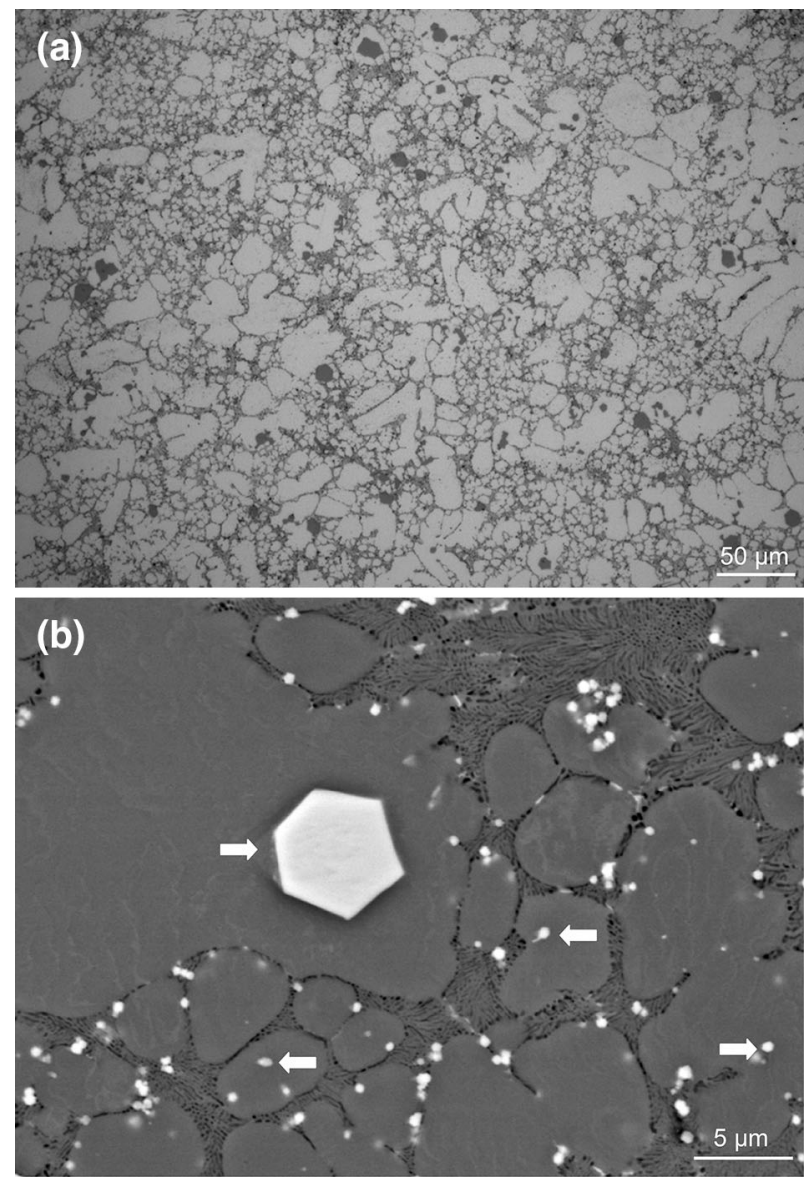

Fig. 1-(a) Optical micrograph showing the two typical microstructures with different cooling rates in the die-cast $\mathrm{Al}-5.3 \mathrm{Mg}-2.4 \mathrm{Si}$ $0.6 \mathrm{Mn}-1.0 \mathrm{Fe}$ alloy, and it is found that some coarse $\alpha$-AlFeMnSi particles are wrapped by the $\alpha$-Al grains. (b) Backscattered electron SEM image shows that besides a coarse $\alpha$-AlFeMnSi intermetallic particle formed in the shot sleeve, some fine $\alpha$-AlFeMnSi intermetallic particles formed in the die cavity are also located inside $\alpha$-Al grains, as shown by the arrows. cavity under a higher cooling rate (about $10^{3} \mathrm{~K} / \mathrm{s}$ ). The gray inter-dendritic regions show a eutectic microstructure composed of the $\alpha-\mathrm{Al}$ and $\mathrm{Mg}_{2} \mathrm{Si}$ phases. ${ }^{[13]}$ Similar with the solidification of $\alpha$-Al phase, the $\alpha$-AlFeMnSi intermetallics are also precipitated in two different solidification stages in the HPDC process: one is in the shot sleeve, and the other is in the die cavity, resulting in two different sizes. It should be noted that many coarse $\alpha$-AlFeMnSi intermetallics with the compact morphology are located inside the $\alpha$-Al dendrite fragments (Figure 1(a)). Figure 1(b) is an enlarged backscattered electron SEM image showing a coarse $\alpha$-AlFeMnSi intermetallic particle inside one $\alpha$-Al dendrite fragment and some fine $\alpha$-AlFeMnSi intermetallic particles inside the fine globular $\alpha$-Al grains, as shown by the arrows, although most of the fine $\alpha$-AlFeMnSi intermetallic particles are found at the grain boundary. Furthermore, the composition of both coarse and fine $\alpha$-AlFeMnSi intermetallic particles inside the $\alpha$-Al grains are identified by the SEM/TEM-EDS analysis, and find that they have a similar chemistry close to $\mathrm{Al}_{12}(\mathrm{Fe}, \mathrm{Mn})_{3} \mathrm{Si}$ (Table I). The ratio of $\mathrm{Mn}$ to $\mathrm{Fe}$ of $\alpha-\mathrm{Al}_{12}(\mathrm{Fe}, \mathrm{Mn})_{3} \mathrm{Si}$ intermetallic particles is about 0.50 and 0.52 , respectively. The result above suggests that $\alpha-\mathrm{Al}_{12}(\mathrm{Fe}, \mathrm{Mn})_{3} \mathrm{Si}$ intermetallic particles formed in the shot sleeve or in the die cavity may act as potential nucleation sites for $\alpha-\mathrm{Al}$ phase.

\section{B. Dynamic Observation of Nucleation Particles by $3 D$ SEM Ultramicrotomy}

3D SEM ultramicrotomy, combining a low voltage SEM with a ultramicrotomy technique, was used to conduct statistical analysis of the possible nucleation sites $\left(\alpha-\mathrm{Al}_{12}(\mathrm{Fe}, \mathrm{Mn})_{3} \mathrm{Si}\right.$ intermetallics $)$ inside the nucleated phase ( $\alpha$-Al grains) in 3D space. A total of 593 serial cross-section images were obtained by using $3 \mathrm{D}$ SEM ultramicrotomy. Figure 2(a) is the first SEM ultramicrotomy cross-section image showing a total of 27 grains in this area. It is found in Figure 2(a) that many $\alpha$-Al grains contain one or more $\alpha-\mathrm{Al}_{12}(\mathrm{Fe}, \mathrm{Mn})_{3} \mathrm{Si}$ intermetallic particles, (e.g., grains 11 and 26). Although a majority of $\alpha$-Al grains do not contain $\alpha-\mathrm{Al}_{12}(\mathrm{Fe}, \mathrm{Mn})_{3-}$ $\mathrm{Si}$ intermetallic particles in Figure 2(a), some intermetallic particles may appear in the later images of the series (e.g., grains 6 and 7 in Figure 2(b), which is the twentieth sectioning). However, nothing can be found in grains 1 and 2 through the whole 593 serial images, which may be because grains 1 and 2 are located at the edge of the sample so that $\alpha-\mathrm{Al}_{12}(\mathrm{Fe}, \mathrm{Mn})_{3} \mathrm{Si}$ intermetallic particles inside grains 1 and 2 cannot be observed.

In order to highlight the ultramicrotomy technique, Figure 3 exhibits a series of backscattered electron SEM images obtained on the cross sections of one $\alpha$-Al grain labeled as "A" with a sectioning depth of $30 \mathrm{~nm}$ each time. The serial number is marked on the top-right corner of each SEM image. It is clear that the "A" grain is basically not seen in Figure 3(a), which is number 56 of 593 sectioning images. Figure 3(b) shows the image after 19 sectioning (No. 75), the "A" grain is observed. With the increase of sectioning depth, the cross section of the "A" grain becomes larger, which indicates that 
Table I. Compositions of $\alpha$-AlFeMnSi Intermetallics Inside $\alpha$-Al Grains in the Die-Cast Al-5.3Mg-2.4Si-0.6Mn-1.0Fe (wt pet) Alloy

\begin{tabular}{lccccc}
\hline Composition & $\mathrm{Al}$ & $\mathrm{Fe}$ & $\mathrm{Mn}$ & $\mathrm{Si}$ & $\mathrm{Mn} / \mathrm{Fe}$ \\
\hline Coarse $\alpha-\mathrm{AlFeMnSi}$ & 76.64 & 11.83 & 5.95 & 6.27 & 0.50 \\
Fine $\alpha-\mathrm{AlFeMnSi}$ & 75.47 & 12.16 & 6.28 & 6.09 & 0.52 \\
\hline
\end{tabular}
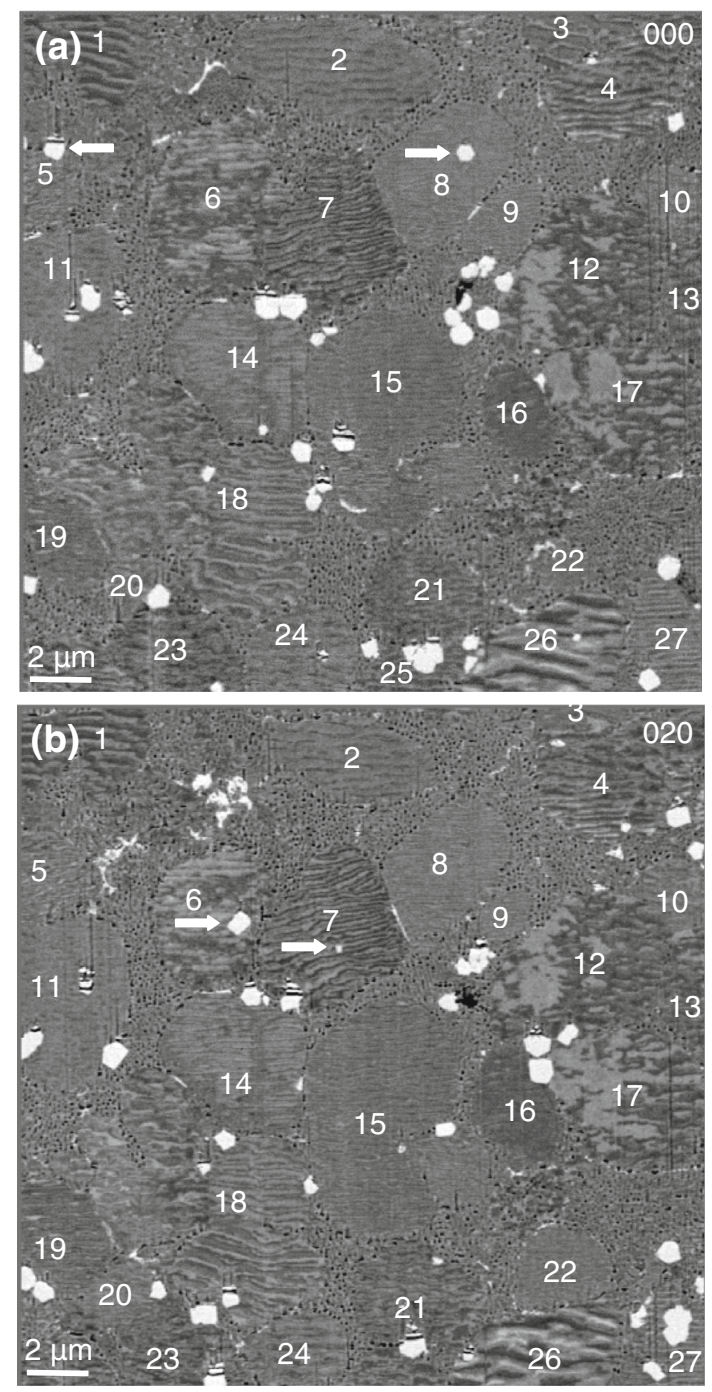

Fig. 2-(a) The first 3D SEM ultramicrotomy cross-section image showing a total of 27 grains in this area. Among these 27 grains, at least one $\alpha-\mathrm{Al}_{12}(\mathrm{Fe}, \mathrm{Mn})_{3} \mathrm{Si}$ intermetallic particle can be directly observed inside the grains $5,8,11,14,15,18,23,24$, and 26; $(b)$ the twentieth cross-section image displays that old $\alpha-\mathrm{Al}_{12}(\mathrm{Fe}, \mathrm{Mn})_{3} \mathrm{Si}$ intermetallics disappear (e.g., in grains 5 and 8$)$, and new $\alpha-\mathrm{Al}_{12}(\mathrm{Fe}, \mathrm{Mn})_{3}$ $\mathrm{Si}$ intermetallics appear (e.g., in grains 6 and 7) with the following serial sectioning, as labeled by the arrows. The number at the topright corner represents the serial number of ultramicrotomy slice.

the sectioning is closer to the center of the " $\mathrm{A}$ " grain after 88 sectioning (No. 144) in Figure 3(c). Further sliding process, an intermetallic particle marked by a white arrow begins to appear in Figure 3(d) after 90 sectioning (No. 146). Its size reaches to the maximum in 100 sectioning (No. 156) as shown in Figure 3(e), and then this intermetallic particle basically disappears after 107 sectioning (No. 163) as displayed in Figure 3(f). During this process, the whole sectioning depth is about $510 \mathrm{~nm}$. After that the cross section of the "A" grain becomes smaller gradually and disappeared completely after 226 sectioning (No. 282), this evolution process is shown from Figure 3(g) to (i). It should be emphasized that a series of backscattered electron SEM images in Figure 3 not only confirm the existence of a $\alpha-\mathrm{Al}_{12}$ $(\mathrm{Fe}, \mathrm{Mn})_{3} \mathrm{Si}$ intermetallic inside one " $\mathrm{A}$ " grain but also confirm that no other particles are observed in this " $\mathrm{A}$ " grain within the resolution limit of this technique.

The results of a statistical analysis of all 593 serial SEM images (equivalent to $18 \mu \mathrm{m}$ in depth) are presented in Table II. In the analyzed volume of $23 \times 23 \times 18 \mu \mathrm{m}^{3}$, there are $94 \alpha$-Al grains, out of which 84 grains are found to contain at least one $\alpha-\mathrm{Al}_{12}(\mathrm{Fe}, \mathrm{Mn})_{3} \mathrm{Si}$ intermetallic particle, and 10 grains (including 8 grains located at the edge of the examined volume) do not contain any one $\alpha-\mathrm{Al}_{12}(\mathrm{Fe}, \mathrm{Mn})_{3} \mathrm{Si}$ intermetallic particle. This represents a 89.4 pct confidence that most of $\alpha$-Al grains contain at least one $\alpha-\mathrm{Al}_{12}(\mathrm{Fe}, \mathrm{Mn})_{3} \mathrm{Si}$ intermetallic particle which is responsible for heterogeneous nucleation of the $\alpha$-Al grains. In fact, if only considering new emerging grains excluding 27 grains displayed in the first image (Figure 2(a)), this probability will be rise to 92.5 pct. Figure 4 further presents a 3D volumetric reconstruction from serial slices, which shows the morphology and spatial distribution of $\alpha-\mathrm{Al}_{12}(\mathrm{Fe}, \mathrm{Mn})_{3} \mathrm{Si}$ intermetallic particles in $\alpha-\mathrm{Al}$ grains: red and green apply $\alpha-\mathrm{Al}_{12}(\mathrm{Fe}, \mathrm{Mn})_{3} \mathrm{Si}$ intermetallic and $\mathrm{Al} / \mathrm{Mg}_{2} \mathrm{Si}$ eutectic, respectively. Obviously, 3D SEM ultramicrotomy provides a more intuitive observation and statistical result, which is unobtainable only by the conventional 2D techniques, as shown in Figure 1.

\section{Nature of $\alpha-\mathrm{Al}_{12}(\mathrm{Fe}, \mathrm{Mn})_{3} \mathrm{Si}$ Intermetallic Particle}

Figure 5(a) shows the XRD spectrum of the as-cast Al-5.3Mg-2.4Si-0.6Mn-1.0Fe alloy. Apart from the reflections from $\alpha$-Al matrix and $\mathrm{Mg}_{2} \mathrm{Si}$ eutectic phase, some additional peaks are also detected. These additional peaks should come from the $\alpha-\mathrm{Al}_{12}(\mathrm{Fe}, \mathrm{Mn})_{3} \mathrm{Si}$ intermetallic particles and are close to the reflections of $\mathrm{Al}_{15}(\mathrm{FeMn})_{3} \mathrm{Si}_{2}$ phase indentified by Cooper in Al-FeSi-Mn alloy $\left(a=1.256 \mathrm{~nm}\right.$, ICSD: 71-4015), ${ }^{[15]}$ as shown in Figure 5(b). This result suggests that the $\alpha$ $\mathrm{Al}_{12}(\mathrm{Fe}, \mathrm{Mn})_{3} \mathrm{Si}$ intermetallic particle may have a similar body-centered cubic (BCC) structure with the $\mathrm{Al}_{15}$ $(\mathrm{FeMn})_{3} \mathrm{Si}_{2}$ phase. The lattice parameter of $\alpha-\mathrm{Al}_{12}$ $(\mathrm{Fe}, \mathrm{Mn})_{3} \mathrm{Si}$ intermetallic particle is identified as 1.265 $\mathrm{nm}$ based on the XRD diffraction data (Figure 5(a)). In addition, it should be pointed out that although both 

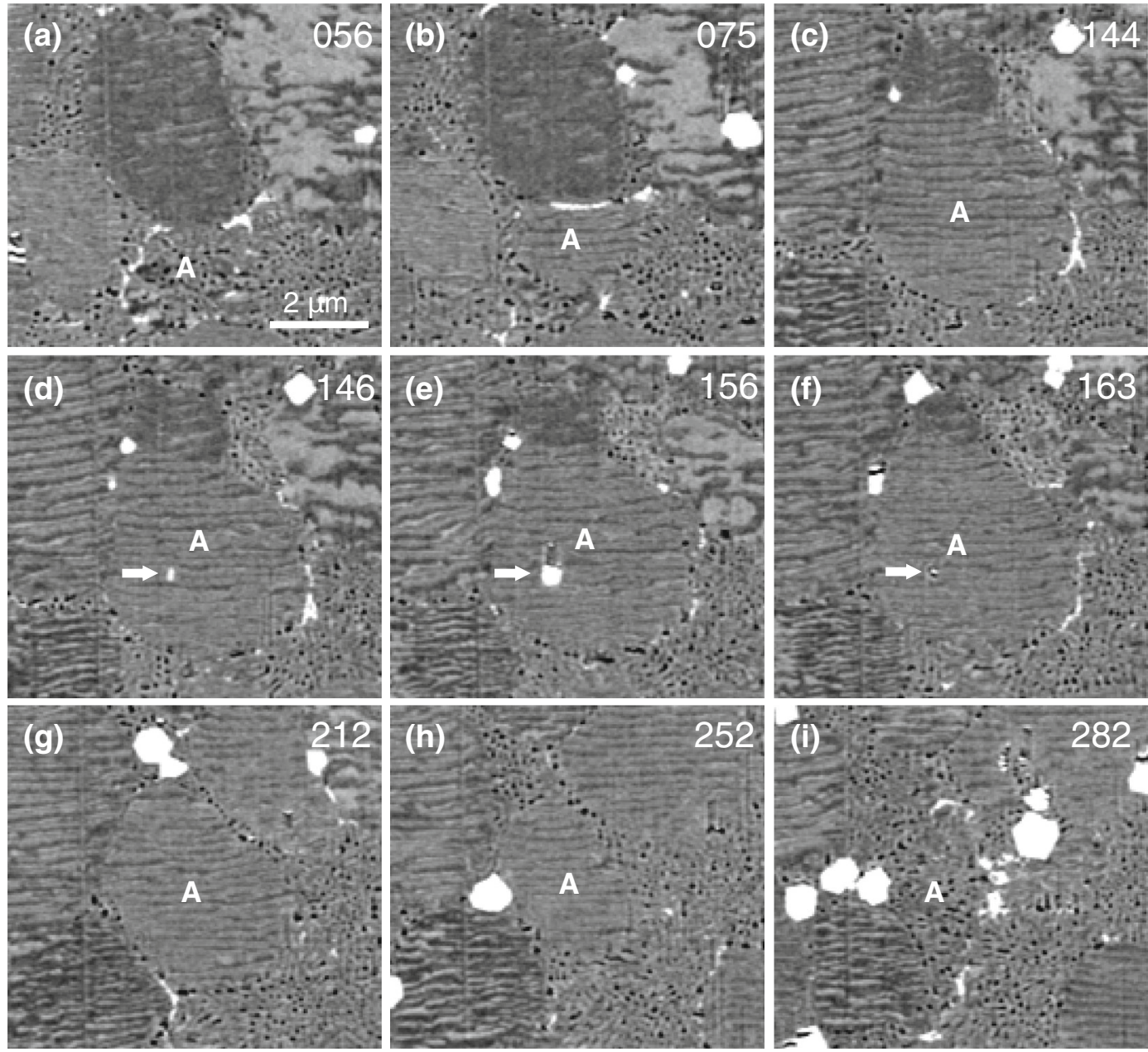

Fig. 3-The dynamic ultramicrotomy process showing a series of cross-section images $(a$ to $i)$ in $30 \mathrm{~nm}$ steps to demonstrate the appearance and disappearance of only one $\alpha-\mathrm{Al}_{12}(\mathrm{Fe}, \mathrm{Mn})_{3} \mathrm{Si}$ intermetallic inside one "A" grain. The number at the top-right corner represents the serial number of ultramicrotomy slice.

Table II. Statistical Analysis for all 94 Grains in 593 Photos with Depth from 0 to 17,790 $\mathrm{nm}$ by 3D SEM Ultramicrotomy

\begin{tabular}{lccccc}
\hline $\begin{array}{l}\text { Total } \\
\text { No. of } \\
\text { Grains }\end{array}$ & $\begin{array}{c}\text { No. of Grains } \\
\text { Located at the } \\
\text { Edge Without } \\
\alpha \text {-AlFeMnSi }\end{array}$ & $\begin{array}{c}\text { No. of Grains } \\
\text { Without } \alpha \text {-AlFeMnSi } \\
\text { Because of Cutting }\end{array}$ & $\begin{array}{c}\text { No. of with } \\
\text { No. of Grains } \\
\text { no } \alpha \text {-AlFeMnSi }\end{array}$ & $\begin{array}{c}\alpha \text {-AlFeMnSi } \\
\text { ocated in } \\
\text { Al Grain }\end{array}$ & Probability \\
\hline 94 & 5 & 3 & 2 & 84 & 89.4 pct \\
\hline
\end{tabular}

peaks from the $\alpha-\mathrm{Al}_{12}(\mathrm{Fe}, \mathrm{Mn})_{3} \mathrm{Si}$ phase and the $\mathrm{Al}_{15}$ $(\mathrm{FeMn})_{3} \mathrm{Si}_{2}$ phase in Figures $5(\mathrm{a})$ and (b) show the similar diffraction behavior, the reflections from $\alpha-\mathrm{Al}_{12}(\mathrm{Fe}, \mathrm{Mn})_{3} \mathrm{Si}$ phase are shifted toward the lower angle. This shift may be attributable to the difference in the chemical composition of two phases.

TEM and HRTEM were used to investigate the crystal structure and lattice parameter of the $\alpha-\mathrm{Al}_{12}(\mathrm{Fe}, \mathrm{Mn})_{3} \mathrm{Si}$ intermetallic particle (Figure 6). The corresponding select area diffraction patterns (SADP) and the fast Fourier transform (FFT) pattern are shown as insets at the upper right corner of TEM micrographs. In Figure 6(a), the $\alpha-\mathrm{Al}_{12}(\mathrm{Fe}, \mathrm{Mn})_{3} \mathrm{Si}$ intermetallic particle displays a hexagonal morphology. A hexagonal lattice projection with spacing of the $\{110\}_{\alpha-\mathrm{AlFeMnSi}}$ along the $\langle 111\rangle_{\alpha-\mathrm{AlFeMnSi}}$ zone axis of a BCC structure is displayed in Figure 6(b). The plane spacing of $\{110\}_{\alpha-}$ AlFeMnSi by HRTEM measuring is about $0.895 \mathrm{~nm}$, which can be used to further deduce the lattice parameter of $\alpha-\mathrm{Al}_{12}(\mathrm{Fe}, \mathrm{Mn})_{3} \mathrm{Si}$ intermetallic as $1.265 \mathrm{~nm}$, which agrees well with the XRD result. In addition, the angle between the faceted planes of this intermetallic particle is measured as about $123 \mathrm{deg}$, which suggests that the $\alpha-\mathrm{Al}_{12}(\mathrm{Fe}, \mathrm{Mn})_{3} \mathrm{Si}$ intermetallic may be $\{110\}$ faceted, because the angle between $\{110\}$ planes in BCC lattice is $120 \mathrm{deg}$. This result indicates that the 


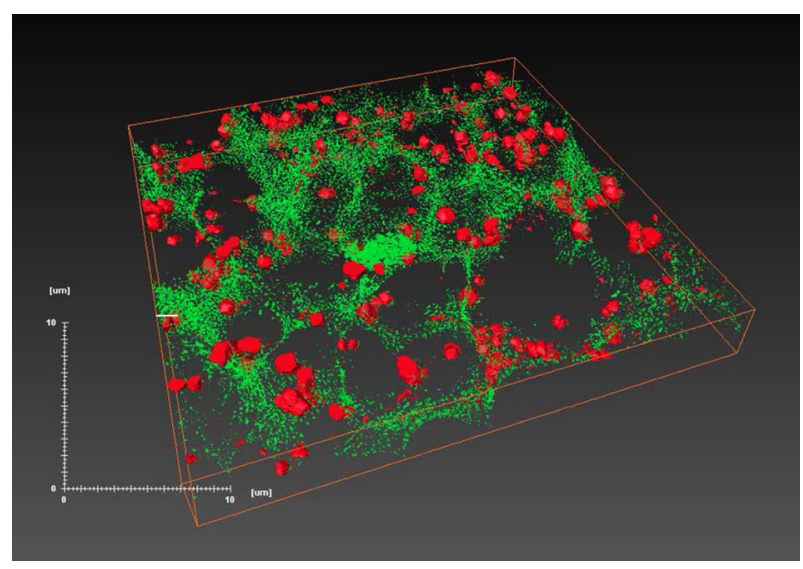

Fig. 4-3D volumetric reconstruction to showing the morphology and spatial distribution of $\alpha-\mathrm{Al}_{12}(\mathrm{Fe}, \mathrm{Mn})_{3} \mathrm{Si}$ intermetallic particles: red and green apply to $\alpha-\mathrm{Al}_{12}(\mathrm{Fe}, \mathrm{Mn})_{3} \mathrm{Si}$ intermetallic particles and $\mathrm{Al} / \mathrm{Mg}_{2} \mathrm{Si}$ eutectic, respectively. For a video summary of this $3 \mathrm{D}$ volumetric reconstruction, see the "3D volumetric reconstruction" file with the Supplementary Material available online.

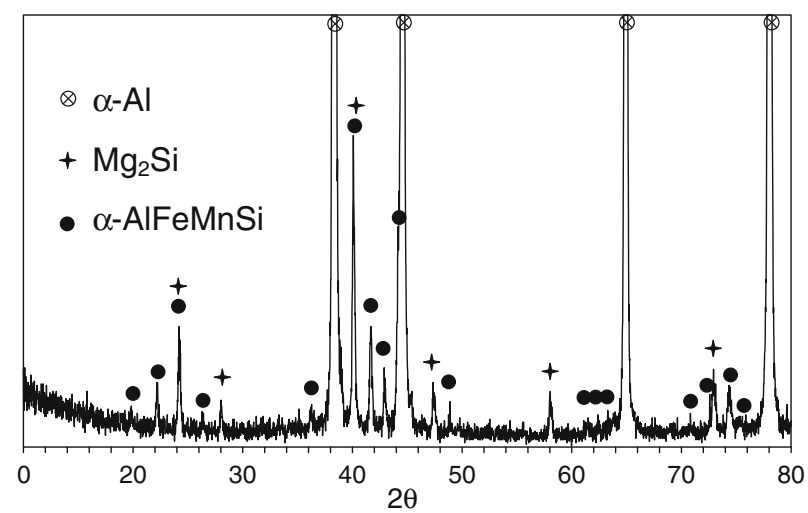

(a)

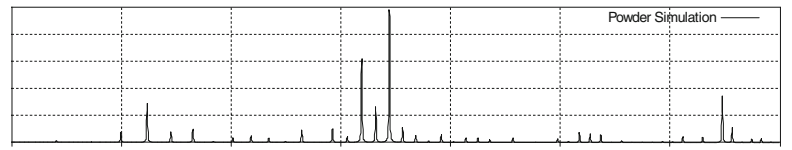

(b)

Fig. 5- (a) XRD spectrums of the Al-5.3Mg-2.4Si-0.6Mn-1.0Fe alloy and $(b)$ the diffraction peaks of the $\mathrm{Al}_{15} \mathrm{FeMn}_{3} \mathrm{Si}_{2}$ phase (ICSD: 71$\left.4015,{ }^{[15]}\right)$.

$\alpha-\mathrm{Al}_{12}(\mathrm{Fe}, \mathrm{Mn})_{3} \mathrm{Si}$ intermetallic particle may display 6 $\{110\}_{\alpha-\mathrm{AlFeMnSi}}$ faceted planes along the $[111]_{\alpha-\mathrm{AlFeMnSi}}$ growth direction resulting in a typical hexagonal morphology, as shown in Figures 1 and 6.

As the nucleation only happens on the naturally exposed plane of a solid particle, it is necessary to further confirm the natural exposed plane of $\alpha-\mathrm{Al}_{12}(\mathrm{Fe}, \mathrm{Mn})_{3} \mathrm{Si}$ intermetallic. A HRTEM image at the interface between $\alpha-\mathrm{Al}_{12}(\mathrm{Fe}, \mathrm{Mn})_{3} \mathrm{Si}$ intermetallic particle and $\alpha$-Al phase under the $[100]_{\alpha-\mathrm{AlFeMnSi}}$ zone axis is obtained in Figure 7(a). Figure 7(b) gives the corresponding FFT patterns. Since there is no any crystallographic match between the $\alpha-\mathrm{Al}_{12}(\mathrm{Fe}, \mathrm{Mn})_{3} \mathrm{Si}$ intermetallic particle and the $\alpha$-Al matrix, some lattice streaks cannot be found in the $\alpha-\mathrm{Al}$ phase. According to
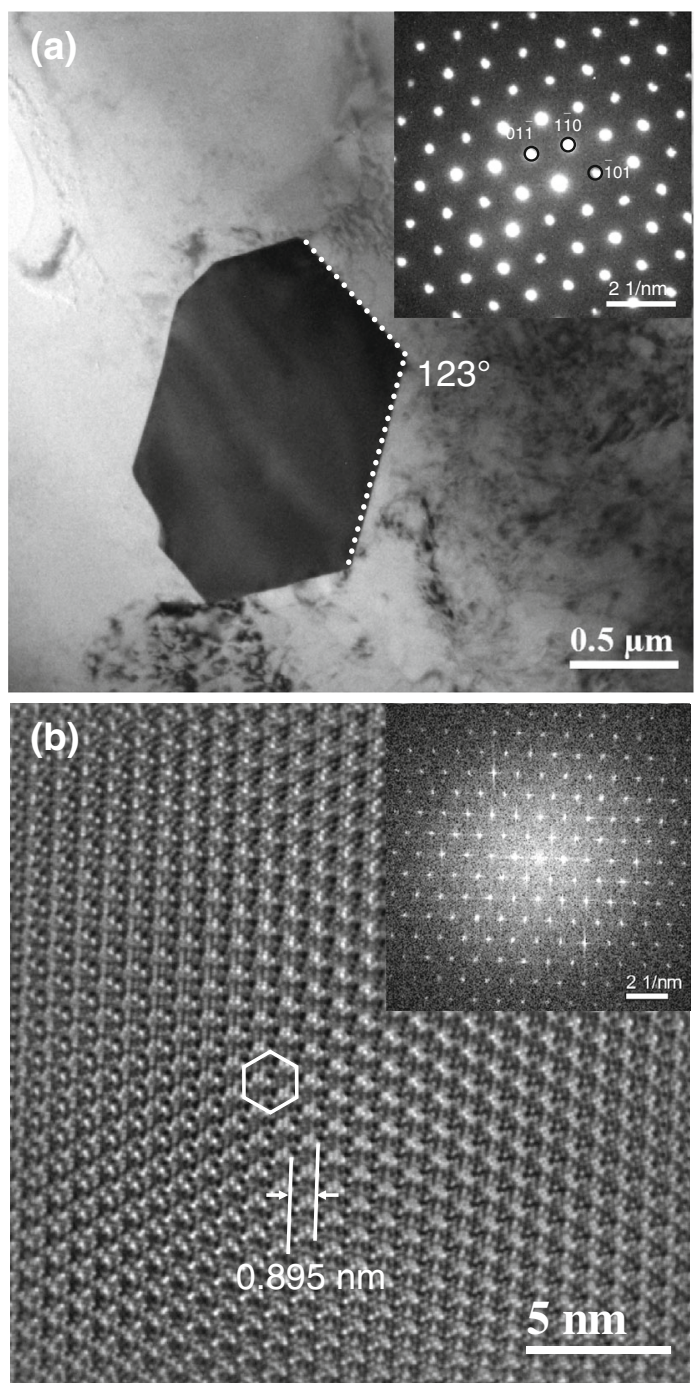

Fig. 6-(a) TEM and (b) HRTEM images from the fine $\alpha$ - $\mathrm{Al}_{12}$ $(\mathrm{Fe}, \mathrm{Mn})_{3} \mathrm{Si}$ intermetallic particle showing a hexagonal morphology and a projection of the unit cell and spacing of the $\{110\}$ with $\langle 111\rangle$ zone axis. The corresponding SADP and FFT patterns are given as the insets at the top-right corner, respectively. The indexes of diffraction spots are from the $\alpha-\mathrm{Al}_{12}(\mathrm{Fe}, \mathrm{Mn})_{3} \mathrm{Si}$ intermetallic particle.

the FFT patterns and the plane spacing $(0.895 \mathrm{~nm})$ of $(011)_{\alpha-A l F e M n S i}$ plane, Figure 7 not only confirms that the naturally exposed faceted plane of $\alpha-\mathrm{Al}_{12}(\mathrm{Fe}, \mathrm{Mn})_{3}$ $\mathrm{Si}$ intermetallic belongs to the $\{110\}_{\alpha-\mathrm{AlFeMnSi}}$ planes, but also further verifies that the $\alpha-\mathrm{Al}_{12}(\mathrm{Fe}, \mathrm{Mn})_{3} \mathrm{Si}$ intermetallic has BCC structure because of the absence of the spots of $h+k+1 \neq 2 n$ in its [100] zone axis pattern.

\section{Orientation Relationships Between $\alpha-\mathrm{Al}_{12}(\mathrm{Fe}, \mathrm{Mn})_{3} \mathrm{Si}$ Intermetallic Particle and $\alpha$-Al Phase}

Figure 8(a) shows a HRTEM image of the interface between $\alpha-\mathrm{Al}_{12}(\mathrm{Fe}, \mathrm{Mn})_{3} \mathrm{Si}$ intermetallic particle and $\alpha$-Al phase. By analyzing the matching interface (Figure 8(a)) and the corresponding filtered FFT pattern with the original FFT pattern as inset (Figure 8(b)), a defined orientation relationship can be obtained. The $\alpha-\mathrm{Al}_{12}(\mathrm{Fe}, \mathrm{Mn})_{3} \mathrm{Si}$ intermetallic is viewed along the 

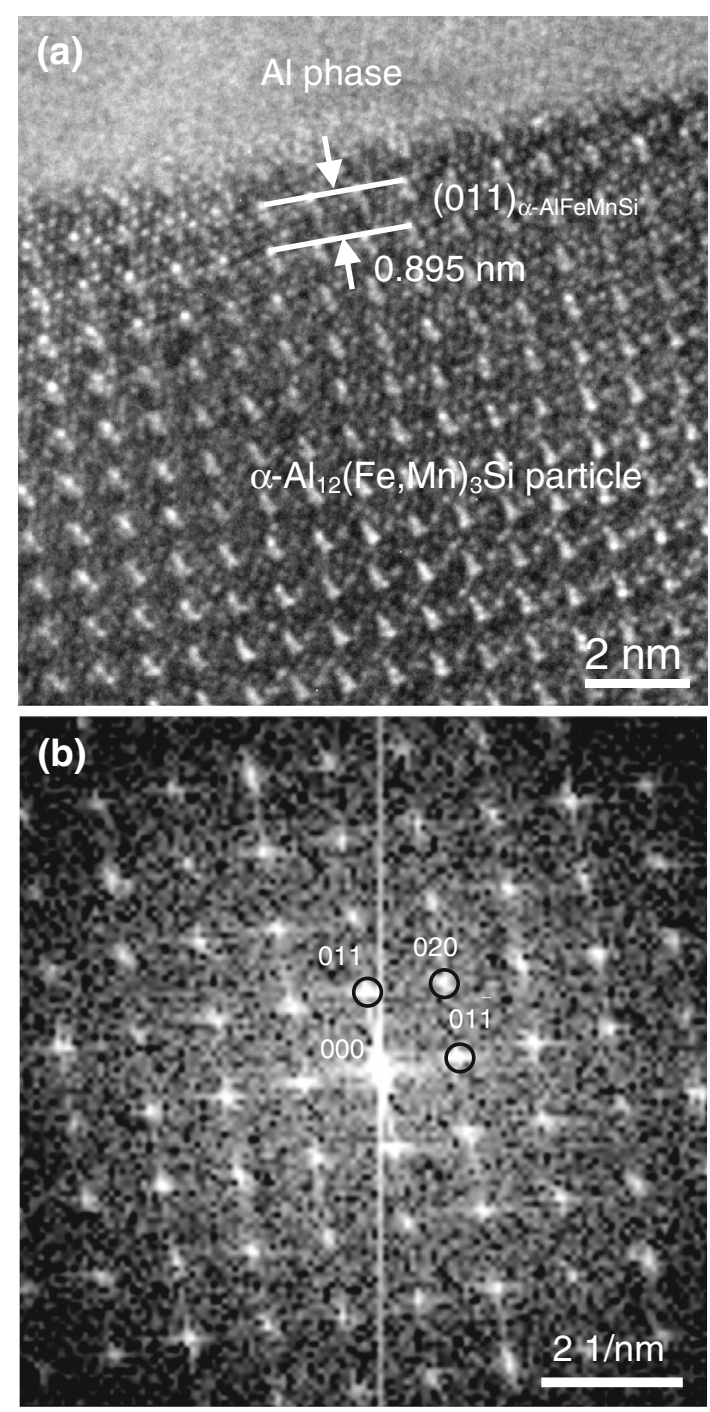

Fig. 7-HRTEM (a) from the $\alpha-\mathrm{Al}_{12}(\mathrm{Fe}, \mathrm{Mn})_{3} \mathrm{Si}$ intermetallic particle along the $[100]_{\alpha-\mathrm{AlFeMnSi}}$ direction to further confirm its structure of $\alpha-\mathrm{Al}_{12}(\mathrm{Fe}, \mathrm{Mn})_{3} \mathrm{Si}$ intermetallic particle and the exposed faceted $\{110\}_{\alpha-\mathrm{AlFeMnSi}}$ planes. The indexes of diffraction spots are from the $\alpha$-AlFeMnSi intermetallic particle.

$[111]_{\alpha-\mathrm{AlFeMnSi}}$ direction, displaying some typical hexagonal lattice streaks, while the $\alpha$-Al phase is aligned along the $[110]_{\mathrm{Al}}$ direction. The $(1 \overline{1} 1)_{\mathrm{Al}}$ plane from $\alpha$-Al phase is almost parallel to the $(1 \overline{1} 0)_{\alpha-\mathrm{AlFeMnSi}}$ plane of $\alpha-\mathrm{Al}_{12}$ $(\mathrm{Fe}, \mathrm{Mn})_{3} \mathrm{Si}$ intermetallic when $[110]_{\mathrm{Al}} / /[111]_{\alpha-\mathrm{AlFeMnSi}}$, there is $\sim 6$ deg deviation between two matching planes (Figure 8). Therefore, the orientation relationships between $\alpha-\mathrm{Al}_{12}(\mathrm{Fe}, \mathrm{Mn})_{3} \mathrm{Si}$ intermetallic particle and $\alpha-\mathrm{Al}$ phase should be described as $(1 \overline{1} 0)_{\alpha-\mathrm{AlFeMnSi}} \sim 6 \mathrm{deg}$ from $(1 \overline{1} 1)_{\mathrm{Al}}$ and $[111]_{\alpha-\mathrm{AlFeMnSi}} / /[110]_{\mathrm{Al}}$. Undoubtedly, the naturally exposed faceted plane of this matching $\alpha$ $\mathrm{Al}_{12}(\mathrm{Fe}, \mathrm{Mn})_{3} \mathrm{Si}$ intermetallic particle still belongs to the $\{110\}_{\alpha-\mathrm{AlFeMnSi}}$ planes family.

\section{DISCUSSION}

A prerequisite for solid particles to act as heterogeneous nucleation sites of the $\alpha$-Al phase is that they have
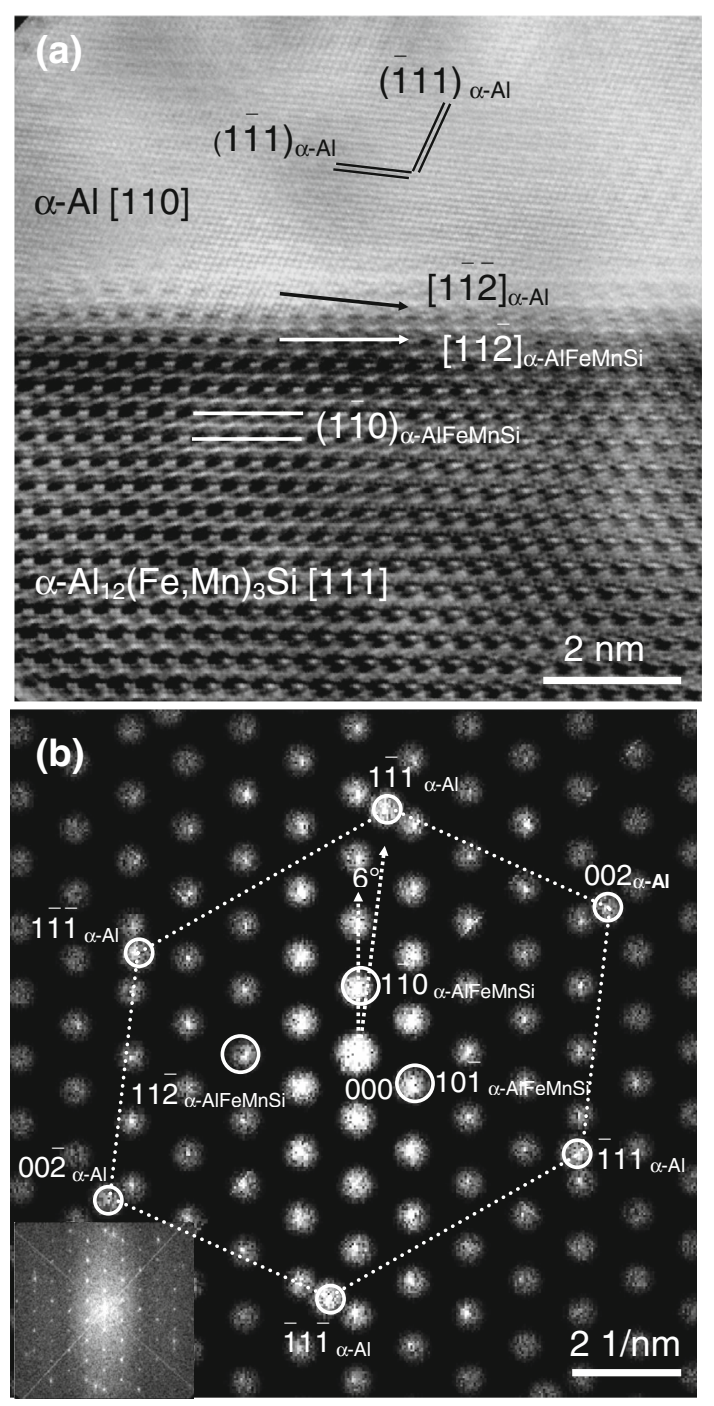

Fig. 8- (a) HRTEM image of the interface between $\alpha-\mathrm{Al}_{12}(\mathrm{Fe}, \mathrm{Mn})_{3-}$ $\mathrm{Si}$ intermetallic particle and $\alpha$-Al phase, where the $\alpha-\mathrm{Al}_{12}(\mathrm{Fe}, \mathrm{Mn})_{3} \mathrm{Si}$ intermetallic particle is viewed along the $[111]_{\alpha-\mathrm{AlFeMnSi}}$ direction, and the $\alpha$-Al phase is along the $[110]_{\alpha-\mathrm{Al}}$ direction; and $(b)$ the corresponding filtering FFT patterns, the original FFT pattern is given as the inset at the lower left corner.

to exist in the melt prior to the formation of $\alpha$-Al phase. To check this, PANDAT software and Al-DATA ${ }^{[16]}$ were used to calculate the equilibrium phase diagram of the multi-component Al-Mg-Si-Mn-Fe system. Figure 9 shows a vertical section of the equilibrium phase diagram of the $\mathrm{Al}-5.3 \mathrm{Mg}-2.4 \mathrm{Si}-0.6 \mathrm{Mn}$ system as a function of the Fe content. According to the result in Figure 9, the primary phase is the $\alpha$-Al phase when Fe content is $<0.25 \mathrm{pct}$, the primary phase is $\alpha-\mathrm{Al}_{12}$ $(\mathrm{Fe}, \mathrm{Mn})_{3} \mathrm{Si}$ intermetallics when $\mathrm{Fe}$ content is between 0.25 and 1.40 pct, while the primary phase will be $\beta$ - $\mathrm{Al}_{13} \mathrm{Fe}_{4}$ intermetallic when $\mathrm{Fe}$ content is more than 1.40 pct. Therefore, for the experimental alloy with 1.0 pct $\mathrm{Fe}$, the solidification starts at about $922 \mathrm{~K}$ $\left(649^{\circ} \mathrm{C}\right)$ by the precipitation of primary $\alpha-\mathrm{Al}_{12}$ $(\mathrm{Fe}, \mathrm{Mn})_{3} \mathrm{Si}$ intermetallic and followed by the formation of $\alpha$-Al phase at $893 \mathrm{~K}\left(620^{\circ} \mathrm{C}\right)$. The solidification process is finished at $863 \mathrm{~K}\left(590{ }^{\circ} \mathrm{C}\right)$ through a pseudo- 


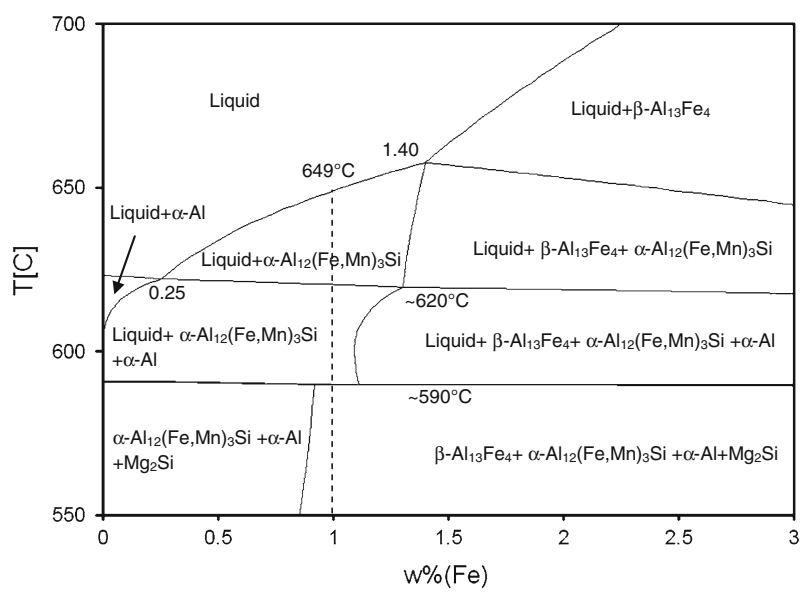

Fig. 9-Vertical section of equilibrium phase diagram of the A1-5.3Mg-2.4Si-0.6Mn alloy with varying $\mathrm{Fe}$ content calculated by the PANDAT software.

binary eutectic reaction between $\alpha$-Al phase and $\mathrm{Mg}_{2} \mathrm{Si}$ phase. It is clear from this solidification sequence that $\alpha-\mathrm{Al}_{12}(\mathrm{Fe}, \mathrm{Mn})_{3} \mathrm{Si}$ intermetallics as primary phases do exist in the alloy melt prior to the formation of $\alpha-\mathrm{Al}$ phase, and may act as potential sites for the nucleation of $\alpha$-Al phase.

The statistical analysis of the probability of primary $\alpha-\mathrm{Al}_{12}(\mathrm{Fe}, \mathrm{Mn})_{3} \mathrm{Si}$ intermetallic particles located inside $\alpha$ $\mathrm{Al}$ grains (Table II) shows that almost 90 pet $\alpha$-Al grains contain at least one $\alpha-\mathrm{Al}_{12}(\mathrm{Fe}, \mathrm{Mn})_{3} \mathrm{Si}$ intermetallic particle. In consideration of the grains located at the edge of the analyzed volume and fine $\alpha-\mathrm{Al}_{12}(\mathrm{Fe}, \mathrm{Mn})_{3} \mathrm{Si}$ intermetallic particles with a size smaller than the sectioning steps $(30 \mathrm{~nm})$, this probability should be closer to 100 pet. However, this observation for the spatial distribution of primary $\alpha-\mathrm{Al}_{12}(\mathrm{Fe}, \mathrm{Mn})_{3} \mathrm{Si}$ intermetallic particles inside $\alpha$-Al grains is not adequate to confirm the nucleation behavior. This is because intermetallic particles located at the solid/liquid interface during solidification may be engulfed inside the grains without having contributed to a nucleation event. ${ }^{[1]]}$ Therefore, the result from 3D SEM ultramicrotomy can only suggest that the primary $\alpha-\mathrm{Al}_{12}(\mathrm{Fe}, \mathrm{Mn})_{3} \mathrm{Si}$ intermetallic particles are highly likely to act as nucleation sites for the formation of $\alpha$-Al phase. A necessary and sufficient condition for heterogeneous nucleation is the existence of a coherent or semi-coherent interface between the wrapped $\alpha-\mathrm{Al}_{12}(\mathrm{Fe}, \mathrm{Mn})_{3} \mathrm{Si}$ intermetallics and the $\alpha$-Al phase, because such interface can often provide a much lower nucleation barrier than the incoherent interface. Therefore, the lattice misfit at the $\alpha-\mathrm{Al} / \alpha-\mathrm{Al}_{12}(\mathrm{Fe}, \mathrm{Mn})_{3} \mathrm{Si}$ interface needs still to be used to estimate quantitatively the nucleation potency. In other words, if the primary $\alpha-\mathrm{Al}_{12}(\mathrm{Fe}, \mathrm{Mn})_{3} \mathrm{Si}$ intermetallic particle can be the nucleation site of $\alpha$-Al phase, this $\alpha-\mathrm{Al}_{12}(\mathrm{Fe}, \mathrm{Mn})_{3} \mathrm{Si}$ intermetallic particle should have a certain matching interface with a smaller misfit with the nucleated $\alpha$-Al phase.

So far, various crystal structures accompanied by different compositions have been proposed for the $\alpha$-AlFeMnSi intermetallics. It was first described as $\mathrm{Al}_{15} \mathrm{FeMn}_{3} \mathrm{Si}_{2}$ with a BCC structure and $a=1.256$ by
Cooper in 1967. ${ }^{[15]}$ However, in 1993, Lai found that the composition of $\alpha$-AlFeMnSi intermetallic was close to $\mathrm{Al}_{19}(\mathrm{Fe}, \mathrm{Mn})_{5} \mathrm{Si}_{2}$, but its structure was actually not stable. ${ }^{[18]}$ It presented two different structures: BCC and simple cubic (SC) with the same $1.263 \mathrm{~nm}$ lattice parameter. It was found that the $\mathrm{BCC}$ structure of $\mathrm{Al}_{19}(\mathrm{Fe}, \mathrm{Mn})_{5-}$ $\mathrm{Si}_{2}$ phase could be transformed into SC structure after heat treatment, depending on the different ratios of $\mathrm{Mn}$ and $\mathrm{Fe}$. Although the critical ratio was not clear, when the Mn content was much lower than that of $\mathrm{Fe}$, the stable crystal structure preferred to have a BCC structure. Moreover, Donnadieu $^{[19]}$ believed that the composition should be described as $\mathrm{Al}_{12}(\mathrm{Fe}, \mathrm{Mn})_{3} \mathrm{Si}$, and that the $\alpha-\mathrm{AlFeMnSi}$ phase had a SC structure when $\mathrm{Mn} / \mathrm{Fe}>3$ and a BCC structure $(a=1.27 \mathrm{~nm})$ when $\mathrm{Mn} / \mathrm{Fe}$ was between 0.2 and 1. Recently, $\mathrm{Kral}^{[20]}$ carried out a crystallographic identification for $\alpha$-AlFeMnSi intermetallics by a combination of EDS, electron backscatter diffraction pattern, and TEM, and they believed that the intermetallics was $\mathrm{Al}_{19} \mathrm{Fe}_{4} \mathrm{MnSi}_{2}$ with a BCC structure $(a=1.256 \mathrm{~nm})$. Overall, although the composition of $\alpha$-AlFeMnSi intermetallics has various differences, its structure is only two types: BCC and SC. And the range of the lattice parameter is located in $1.26 \pm 0.1 \mathrm{~nm}$.

In this work, the $\alpha$-AlFeMnSi intermetallics were identified as $\alpha-\mathrm{Al}_{12}(\mathrm{Fe}, \mathrm{Mn})_{3} \mathrm{Si}$ with a $\mathrm{BCC}$ structure $(a=1.265 \mathrm{~nm})$, and its lattice parameter is about 1.265 $\mathrm{nm}$. This composition differs only slightly from that proposed by Cooper and $\mathrm{Kral},{ }^{[15,20]}$ more possibly due to the difference in $\mathrm{Mn} / \mathrm{Fe}$ ratio. Our results are in agreement with the findings in 6xxx alloy by Donnadie $^{[19]}$ and support Lai's findings that the $\alpha$-AlFeMnSi intermetallic preferred to form BCC structure when $\mathrm{Mn} /$ Fe ratio was between 0.2 to 1 (being 0.5 in our experiment, as shown in Table I). ${ }^{[18]}$

In addition, our experimental results (Figures 6 and 7) show that the primary $\alpha-\mathrm{Al}_{12}(\mathrm{Fe}, \mathrm{Mn})_{3} \mathrm{Si}$ intermetallic particle precipitated from the alloy melt has a faceted morphology, and its naturally exposed external surfaces are $\{110\}$ planes. Identification of the natural exposed surface is important as such planes can only physically act as heterogeneous nucleation substrates.

Based on the HRTEM observation for the matching interface between $\alpha-\mathrm{Al}_{12}(\mathrm{Fe}, \mathrm{Mn})_{3} \mathrm{Si}$ intermetallic particle and $\alpha$-Al phase in Figure 8 , the $\alpha-\mathrm{Al}_{12}(\mathrm{Fe}, \mathrm{Mn})_{3} \mathrm{Si}$ intermetallic particle with $\mathrm{BCC}$ structure has the most closely packed atomic direction being $[111]_{\alpha-\mathrm{AlFeMnSi}}$ on the most closely packed plane being $(110)_{\alpha-\mathrm{AlFeMnSi}}$, which is also identified as the naturally exposed surface for the $\alpha-\mathrm{Al}_{12}(\mathrm{Fe}, \mathrm{Mn})_{3} \mathrm{Si}$ intermetallics. Meanwhile, the $\alpha$-Al phase with a FCC structure has the most closely packed atomic direction being $[110]_{\alpha-\mathrm{Al}}$ on the most closely packed $(1 \overline{1} 1)_{\alpha-\mathrm{Al}}$ plane. The orientation relationships are very similar to the classic $\mathrm{K}-\mathrm{S}$ relationships in Martensite phase transform. ${ }^{[21]}$ At the same time, it should be noted that the matching direction of $\alpha-\mathrm{Al}_{12}(\mathrm{Fe}, \mathrm{Mn})_{3} \mathrm{Si}$ intermetallics is actually the $[11 \overline{1}]_{\alpha-\mathrm{AlFeMnSi}}$ direction, which is located at the exposed $(1 \overline{1} 0)_{\alpha-A l F e M n S i}$ plane and parallel to the solid/substrate interface. Accordingly, the corresponding matching direction of $\alpha$-Al phase is the $[1 \overline{12}]_{\alpha-\mathrm{Al}}$ direction, which is located at the (111) $)_{\alpha-\mathrm{Al}}$ plane, but there is a small $6 \mathrm{deg}$ 
deviation from the $[11 \overline{2}]_{\alpha-A l F e M n S i}$ direction, as seen in Figure 8 . Figure 10 shows a superimposed $[111]_{\alpha-\mathrm{Al}}$ $\mathrm{FeMnSi} / /[110]_{\alpha-\mathrm{Al}}$ stereographic projection, which displays the twin-related crystallographic orientation representation of primary

$\alpha-\mathrm{Al}_{12}(\mathrm{Fe}, \mathrm{Mn})_{3} \mathrm{Si}$ intermetallic and $\alpha-\mathrm{Al}$ phase on the $[111]_{\alpha-\mathrm{AlFeMnSi}}$ direction, where there is a about $6 \mathrm{deg}$ deviation between the $(1 \overline{10})_{\alpha-\mathrm{AlFeMnSi}}$ plane and the $(1 \overline{1} 1)_{\alpha \text {-Al }}$ plane, and between the $[11 \overline{2}]_{\alpha-\mathrm{AlFeMnSi}}$ direction and the $[1 \overline{12}]_{\alpha-\mathrm{Al}}$ direction.

Furthermore, considering the lattice expansion of $\alpha-\mathrm{Al}_{12}(\mathrm{Fe}, \mathrm{Mn})_{3} \mathrm{Si}$ intermetallic and $\alpha$-Al phase at the molten melt, the misfit can be calculated. These results can be shown in Table III. Because both of XRD analysis and HRTEM observation (Figures 5, 6, 7) have confirmed that the lattice parameter of primary $\alpha-\mathrm{Al}_{12}(\mathrm{Fe}, \mathrm{Mn})_{3} \mathrm{Si}$ intermetallic particle is $1.265 \mathrm{~nm}$ at room temperature $\left(293 \mathrm{~K}\left(20^{\circ} \mathrm{C}\right)\right)$, its lattice parameter at $933 \mathrm{~K}\left(660^{\circ} \mathrm{C}\right)$ can be calculated as $1.278 \mathrm{~nm}$ by using the coefficient of thermal expansion from the literature, ${ }^{[22]}$ just like $0.412 \mathrm{~nm}$ for Al at high temperature. ${ }^{[23]}$ From Table III, it is evident that the misfit between $\alpha-\mathrm{Al}_{12}(\mathrm{Fe}, \mathrm{Mn})_{3} \mathrm{Si}$ intermetallic particle and $\alpha$-Al phase presents a decreasing trend when both of

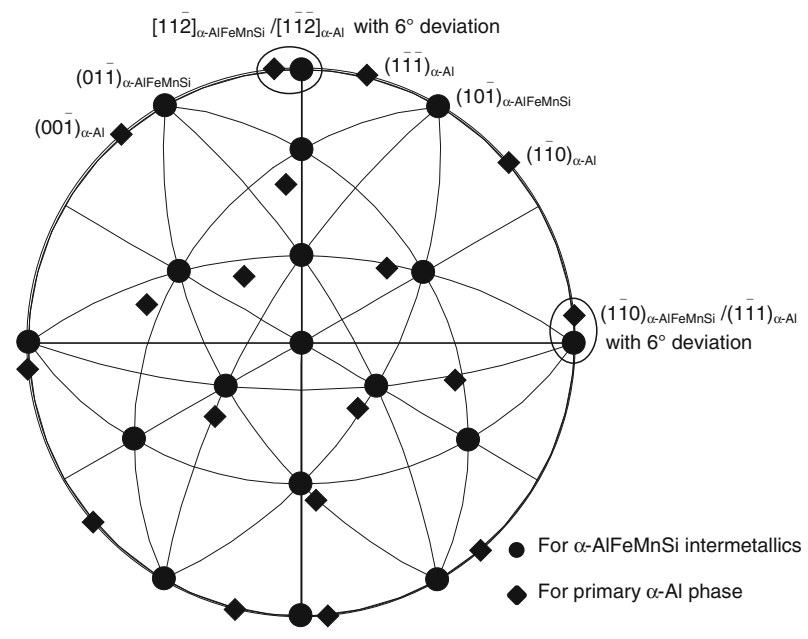

$[111]_{\alpha-A I F e M n s i} / /[110]_{\alpha-A I}$

Fig. $10-$ The stereographic projections of $\alpha-\mathrm{Al}_{12}(\mathrm{Fe}, \mathrm{Mn})_{3} \mathrm{Si}$ intermetallic particle and $\alpha$-Al phases showing the crystallographic orientation representation when the $[111]_{\alpha-\mathrm{AlFeMnSi}}$ direction is parallel to the $[110]_{\alpha-\mathrm{Al}}$ direction. the deviation and lattice expansion are considered, i.e., reduced from 3.86 to 2.76 pct, which means that the nucleation barrier continuously decreased. It should be noted that a 6 deg deviation may minimize the matching difference at the interface between two phases. At the same time, the misfit $\delta^{\prime}$ at $933 \mathrm{~K}\left(660^{\circ} \mathrm{C}\right)$ is only 2.67 pct, which is encouraging, because the misfit is not only well below the limitation given for a good nucleation agent, which is about 12 pct suggested by Bramfitt, ${ }^{[2]}$ but also much smaller than the limited value 5.7 pct for Al systems proposed by the epitaxial nucleation model. ${ }^{[9]}$ Simultaneously, this result also confirms for the first time that the matching interface between $\alpha-\mathrm{Al}_{12}(\mathrm{Fe}, \mathrm{Mn})_{3} \mathrm{Si}$ intermetallic particle and $\alpha-\mathrm{Al}$ phase is semi-coherent on the $(1 \overline{1} 0)_{\alpha-\mathrm{AlFeMnSi}}$ plane along the $[11 \overline{2}]_{\alpha-A l F e M n S i}$ direction with a small misfit strain at the specific orientation relationships configuration. Therefore, it can be said that this semi-coherent interface provides a much lower nucleation barrier for the following $\alpha$-Al phase nucleation.

Finally, according to the statistical analysis in 3D space and the crystallographic matching criteria for potent nucleation, ${ }^{[9,24]}$ we can now confidently conclude that the primary $\alpha-\mathrm{Al}_{12}(\mathrm{Fe}, \mathrm{Mn})_{3} \mathrm{Si}$ intermetallic particles can act as potent substrates for the nucleation of $\alpha$-Al phase during solidification of the selected die-cast Al-5.3Mg-2.4Si-0.6Mn-1.0Fe alloy. However, it should also be realized that not all primary $\alpha-\mathrm{Al}_{12}(\mathrm{Fe}, \mathrm{Mn})_{3} \mathrm{Si}$ intermetallic particles can act as nucleation sites of $\alpha$-Al phase according to the free growth model, ${ }^{[6]}$ and that most of them will be located at the grain boundaries as shown in Figure 1.

It should still be pointed out that the primary $\alpha$ AlFeMnSi intermetallic particles may not always act as the nucleation sites for the $\alpha$-Al phase. A potential nucleation site is often affected by many factors, such as, solidification condition, alloy composition, and solute segregation at the liquid/substrate interface. ${ }^{[9]}$ An appropriate solidification condition, e.g., HPDC, can provide relatively large undercooling to allow more $\alpha$-AlFeMnSi intermetallic particles to be active for heterogeneous nucleation, which may not be possible under the normal solidification, e.g., sand casting. ${ }^{[25]}$ Furthermore, solute segregation is also a very important factor for the heterogeneous nucleation for potent nucleation sites. According to the Gibbs adsorption rule and the epitaxial nucleation model, ${ }^{[9,26]}$ these solute elements may segregate at the interface of $\alpha$-AlFeMnSi intermetallic particle to

Table III. Interface Misfit Calculation Between the $\alpha-\mathrm{Al}_{12}(\mathrm{Fe}, \mathrm{Mn})_{3} \mathrm{Si}$ Intermetallic Particle and the $\alpha$-Al Phase Based on the HRTEM Observation

\begin{tabular}{|c|c|c|c|c|c|c|c|c|}
\hline \multirow[b]{2}{*}{ OR } & \multirow[b]{2}{*}{$\begin{array}{l}\text { Directions Along } \\
\text { the Interface }\end{array}$} & \multirow[b]{2}{*}{$\theta$} & \multicolumn{3}{|c|}{$293 \mathrm{~K}\left(20^{\circ} \mathrm{C}\right)$} & \multicolumn{3}{|c|}{$933 \mathrm{~K}\left(660^{\circ} \mathrm{C}\right)$} \\
\hline & & & $\begin{array}{c}d_{[\mathrm{uvw}] \alpha-\mathrm{AlFeMnSi}} \\
(\mathrm{nm})\end{array}$ & $\begin{array}{l}d_{[\mathrm{uvw}] \alpha-\mathrm{Al}} \\
(\mathrm{nm})\end{array}$ & $\delta(\mathrm{pct})$ & $\begin{array}{c}d_{[\mathrm{uvw}] \alpha-\mathrm{AlFeMnSi}} \\
(\mathrm{nm})\end{array}$ & $\begin{array}{l}d_{[\mathrm{uvw}] \alpha-\mathrm{Al}} \\
(\mathrm{nm})\end{array}$ & $\delta^{\prime}(\mathrm{pct})$ \\
\hline $\begin{array}{l}{[111]_{\alpha-\mathrm{AlFeMnSi}} / /[110]_{\alpha-\mathrm{Al}}} \\
(1 \overline{1} 0)_{\alpha-\mathrm{AlFeMnSi}} / /(1 \overline{1} 1)_{\alpha-\mathrm{Al}} \\
{[111]_{\alpha-\mathrm{AlFeMnSi}} / /[110]_{\alpha-\mathrm{Al}}} \\
(1 \overline{1} 0)_{\alpha-\mathrm{AlFeMnSi}} /(1 \overline{1} 1)_{\alpha-\mathrm{Al}} \\
\quad \text { from } 6 \mathrm{deg}\end{array}$ & $\begin{array}{c}{[11 \overline{2}]_{\alpha-\mathrm{AlFeMnSi}} /} \\
{[1 \overline{1} 2]_{\alpha-\mathrm{Al}}} \\
{[11 \overline{1}]_{\alpha-\mathrm{AlFeMnSi}} /} \\
{[1 \overline{1} 2]_{\alpha-\mathrm{Al}}}\end{array}$ & $\begin{array}{l}0 \\
6 \mathrm{deg}\end{array}$ & 3.099 & $6 \times 0.4973$ & $\begin{array}{l}3.86 \\
3.30\end{array}$ & 3.130 & $6 \times 0.5052$ & $\begin{array}{l}3.27 \\
2.67\end{array}$ \\
\hline
\end{tabular}


influence the structure of interface. For instance, compared with the current experimental alloy, in the die-cast LM24 alloy with the same $\mathrm{Fe}$ content, ${ }^{[27]}$ the heterogeneous nucleation phenomenon could not be observed.

\section{CONCLUSIONS}

1. The primary $\alpha-\mathrm{Al}_{12}(\mathrm{Fe}, \mathrm{Mn})_{3} \mathrm{Si}$ intermetallic particles formed in the die-cast Al-5.3Mg-2.4Si-0.6Mn-1.0Fe alloy are potent substrates for heterogeneous nucleation of the $\alpha$-Al phase, which is supported by the 3D SEM ultramicrotomy statistical analysis (almost 90 pet probability) and the smaller lattice misfit $(2.67 \mathrm{pct})$ between $\alpha-\mathrm{Al}_{12}(\mathrm{Fe}, \mathrm{Mn})_{3} \mathrm{Si}$ intermetallic particle and $\alpha$-Al phase.

2. The primary $\alpha-\mathrm{Al}_{12}(\mathrm{Fe}, \mathrm{Mn})_{3} \mathrm{Si}$ intermetallic particle has a BCC structure with a lattice parameter of $a=1.265 \mathrm{~nm}$ and a faceted morphology with $\{110\}_{\alpha \text {-AlFeMnSi }}$ planes exposed as its natural surfaces.

3. The crystallographic orientation relationships between $\alpha-\mathrm{Al}_{12}(\mathrm{Fe}, \mathrm{Mn})_{3} \mathrm{Si}$ intermetallic particle and $\alpha-\mathrm{Al}$ phase are revealed by the HRTEM observation as $[111]_{\alpha-\mathrm{AlFeMnSi}} / /[110]_{\mathrm{Al}}$ and $(1 \overline{1} 0)_{\alpha-\mathrm{Al}-}$ $\mathrm{FeMnSi} \sim 6$ deg from $(1 \overline{1} 1)_{\alpha-\mathrm{Al}}$.

\section{ACKNOWLEDGMENT}

Financial support from EPSRC through the Grant of "Towards Affordable, Closed-Loop Recyclable Future Low Carbon Vehicle Structures-TARF-LCV" is gratefully acknowledged.

\section{ELECTRONIC SUPPLEMENTARY MATERIAL}

The online version of this article (doi:10.1007/s 11661-014-2346-6) contains supplementary material, which is available to authorized users.

\section{REFERENCES}

1. J.A. Dantzig and M. Rappaz: Solidification, EPFL Press, Lausanne, 2009.

2. M. Volmer and A. Webber: Z. Phys. Chem., 1926, vol. 119, pp. 277-301.

3. K.F. Kelton and A.L. Greer: Nucleation in Condensed Matter, Elsevier, Oxford, 2011.

4. B. Cantor: Phil. Trans. R. Soc. Lond., 2003, vol. 361, pp. 409-17.

5. I. Maxwell and A. Hellawell: Acta Metall., 1975, vol. 23, pp. 22937.

6. A.L. Greer, A.M. Bunn, A. Tronche, P.V. Evans, and D.J. Bristow: Acta Mater., 2000, vol. 48, pp. 2823-35.

7. M.X. Zhang, R.M. Kelly, M.A. Easton, and J.A. Taylor: Acta Mater., 2005, vol. 53, pp. 1427-38.

8. B. Jiang, D. Qiu, M.X. Zhang, P.D. Ding, and L. Gao: J. Alloys. Compd., 2010, vol. 492, pp. 95-98.

9. Z. Fan: Metall. Mater. Trans. A, 2013, vol. 44A, pp. 1409-18.

10. B.S. Murty, S.A. Kori, and M. Chakraborty: Inter. Mater. Rev., 2002, vol. 47, pp. 3-29.

11. X. Zhou, C. Luo, T. Hashimoto, A.E. Hughes, and G.E. Thompson: Corros. Sci., 2012, vol. 58, pp. 299-306.

12. T. Hashimoto, X. Zhou, C. Luo, K. Kawano, G.E. Thompson, A.E. Hughes, P. Skeldon, P.J. Withers, T.J. Marrow, and A.H. Sherry: Scripta Mater., 2010, vol. 63, pp. 835-38.

13. S. Ji, W. Yang, F. Gao, D. Watson, and Z. Fan: Mater. Sci. Eng. A, 2013, vol. 564, pp. 130-39.

14. N.A. Belov, A.A. Aksenov, and D.G. Eskin: Iron in Aluminum Alloys, Taylor \& Francis, London, 2002.

15. M. Cooper: Acta Cryst., 1967, vol. 23, pp. 1106-07.

16. S.L. Chen, S. Daniel, F. Zhang, Y.A. Chang, X.Y. Yan, F.Y. Xie, R. Schmid-Fetzer, and W.A. Oates: CALPHAD, 2002, vol. 26, pp. $175-88$.

17. P.L. Schaffer, D.N. Miller, and A.K. Dahle: Scripta Mater., 2007, vol. 57, pp. 1129-32.

18. Z.H. Lai and C.H. Li: Scripta Metall., 1993, vol. 29, pp. 895-900.

19. P. Donnadieu, G. Lapasset, and T. Sanders: Phil. Mag. Lett., 1994, vol. 70, pp. 319-26.

20. M.V. Kral: Mater. Lett., 2005, vol. 59, pp. 2271-76.

21. S. Morito, H. Tanaka, R. Konishi, T. Furuhara, and T. Maki: Acta Mater., 2003, vol. 51, pp. 1789-99.

22. C.L. Chen and R.C. Thomson: Intermetallics, 2010, vol. 18, pp. $1750-57$.

23. M. Johnsson and L. Eriksson: Z. Metallkd., 1998, vol. 89, pp. 47880.

24. B.L. Bramfitt: Metall. Trans., 1970, vol. 1, pp. 1987-98.

25. J.Y. Hwang, H.W. Doty, and M.J. Kaufman: Mater. Sci. Eng. A, 2008, vol. 488, pp. 496-504.

26. J. Gibbs: The Collected Works of J. Willard Gibbs, Langman, Green and Co, New York, 1928, vol. 1.

27. X. Fang, G. Shao, Y.Q. Liu, and Z. Fan: Mater. Sci. Eng. A, 2007, vols. 445-446, pp. 65-72. 